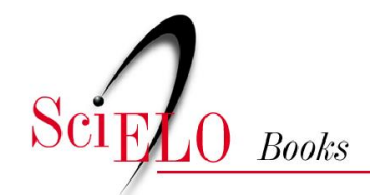

\title{
Maquiavel, o conflito e o desejo de não ser dominado
}

\author{
Helton Adverse
}

ADVERSE, H. Maquiavel, o conflito e o desejo de não ser dominado. In: PINTO, F.M., and BENEVENUTO, F., comps. Filosofia, política e cosmologia: ensaios sobre o renascimento [online]. São Bernardo do Campo, SP: Editora UFABC, 2017, pp. 133-159. ISBN: 978-85-68576-93-9. https://doi.org/10.7476/9788568576939.0008.

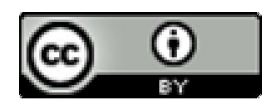

All the contents of this work, except where otherwise noted, is licensed under a Creative Commons Attribution 4.0 International license.

Todo o conteúdo deste trabalho, exceto quando houver ressalva, é publicado sob a licença Creative Commons Atribição $\underline{4.0}$.

Todo el contenido de esta obra, excepto donde se indique lo contrario, está bajo licencia de la licencia $\underline{\text { Creative }}$ Commons Reconocimento 4.0. 
Doutor em Filosofia pela Universidade Federal de Minas Gerais, onde leciona no Departamento de Filosofia. Seu campo de pesquisa recobre autores e temas do Renascimento e da Contemporaneidade, sempre com ênfase na filosofia política. É autor de vários trabalhos, valendo destacar Maquiavel. Política e retórica (Belo Horizonte: Editora UFMG, 2009). 


\section{MAQUIAVEL, O CONFLITO E O DESEJO DE NÃO SER DOMINADO}

Helton Adverse ${ }^{1}$

No conjunto das interpretações contemporâneas de Maquiavel o tema do conflito político recebeu especial atenção, sobretudo a partir da obra de Claude Lefort (1972). Lefort foi o primeiro a dar centralidade ao assunto, trabalhando-o incessantemente ao longo dos anos (LEFORT, 1978; 1992). No entanto, temos a impressão de que uma de suas intuições maiores, a tese de que o desejo do povo é essencialmente negativo, ainda requer elucidação. Minha proposta é tomar a tese em toda sua radicalidade, buscando encontrar nos textos de Maquiavel os elementos que permitem articulá-la, juntando nossos esforços ao trabalho recentemente realizado por importantes comentadores (AMES, 2009; CARDOSO, 2015). Para tanto, adotarei como referencial teórico atual o trabalho de Lefort. Mas, por outro lado, parece-me uma boa estratégia utilizar uma

${ }_{1}$ Professor Associado do Departamento de Filosofia da UFMG. 
referência teórica do próprio Maquiavel, vale dizer, Salústio, uma vez que o trabalho do historiador romano oferece importantes subsídios para compreender o sentido do conflito na obra do florentino.

\section{A Nobreza e a Plebe: Salústio}

Antes de abordar diretamente os textos de Maquiavel, valeria a pena, então, dedicar alguns parágrafos a Salústio, o historiador romano que certamente exerceu um papel importante na formulação do pensamento do florentino, sendo superado somente por Tito Lívio. Esse procedimento se justifica porque vemos "antecipadas" em Salústio algumas das teses mais conhecidas de Maquiavel e, em especial, a formulação da oposição entre a plebe e a nobreza na forma de um antagonismo entre desejos. Explorar essa afinidade terminológica irá nos permitir divisar com mais precisão o teor das proposições maquiavelianas.

As principais obras de Salústio colocam em primeiro plano justamente as dissensões que afetam a vida interna e externa da cidade. Vale lembrar que este é, respectivamente, o tema da Conjuração de Catilina e o de A Guerra de Jugurta. A passagem que gostaríamos de destacar é extraída desta última obra; mais precisamente, um trecho do discurso que o tribuno Memmius dirige à plebe com a intenção de convencê-la a adotar uma medida contrária à decisão do senado de aceitar a paz proposta por Jugurta em condições vergonhosas para o povo romano. Antes de reproduzir a passagem, vale lembrar que o discurso é pronunciado em uma contio, isto é, uma assembleia popular convocada pelo próprio magistrado. Não 
escapa a Salústio que este seja o ambiente propício para expor as dissensões que dividem Roma, e que resultam em grande prejuízo para a república em geral e para a plebe em particular. O discurso de Memmius é, assim, a ocasião para eviscerar aquilo que para Salústio constitui as causas da ruína da liberdade romana: a cobiça da nobreza, a ambição desmesurada do senado que não encontra a resistência da plebe:

Qual esperança vocês podem ter de obter uma aliança fiel e a concórdia entre eles [os nobres] e vocês? Eles querem dominar; vocês querem ser livres ${ }^{2}$; cometer a injustiça, vocês, impedi-la; enfim, eles tratam nossos aliados como inimigos e nossos inimigos como aliados. Em uma tal oposição de sentimentos (divorsis mentibus) há lugar para a paz e a amizade? (SALÚSTIO, 2012a, p. 60, tradução nossa).

O que está em discussão é a conduta venal do senado romano na conclusão do acordo de paz com o rei númida. Jugurta, contando com a corrupção da nobreza romana, consegue, graças ao auxílio do cônsul L. Bestia Calpurnus e de seu legado M. Emilianus Scaurus, um acordo espúrio que lhe permitia dar continuidade a seus projetos políticos de dominação do território númida, a despeito da promessa romana feita a seu primo e rival Aderbal (SALÚSTIO, 2012a, p. 52), filho e legítimo herdeiro do rei Micissipa. Na narrativa de Salústio, a avidez do cônsul ultrapassa o nível da corrupção individual, evidenciando a decadência de toda uma classe que, desprovida de autêntica virtude cívica, coloca em perigo os fundamentos da liberdade romana. O discurso do tribuno, portanto, não é somente a ocasião para a denúncia das causas que destroem

${ }^{2}$ Dominari illi volunt, vos liberi esset (SALÚSTIO, 2012a, p. 60, grifo meu). 
essa liberdade; é também a exortação em sua defesa, que apenas pode ser feita pela plebe. Ao mesmo tempo, Salústio aponta a origem do mal e preconiza sua solução na mobilização da plebe, única parte do corpo político que detém as virtudes necessárias para a salvação da república.

$\mathrm{O}$ discurso de Memmius, então, alcança seu ponto mais alto na explicitação da oposição entre nobres e plebe, a primeira sendo caracterizada por sua ambição e insolência (SALÚSTIO, 2012a, p. 8) e a segunda por sua capacidade de comprometimento com o bem comum. Valeria a pena examinar um pouco mais detalhadamente os elementos que compõem a cena que Salústio acaba de nos descrever tendo em vista sua aproximação com Maquiavel.

Em primeiro lugar está, evidentemente, o conflito e neste ponto específico Salústio não parece inovar. Como observaram Connolly (2007, p. 73) e Kapust (2001, p. 29), a história da liberdade romana, de Tito Lívio a Tácito, sempre foi concebida a partir da noção de antagonismo. Originalmente, o conflito entre Rômulo e Remo, em seguida o conflito contra os reis Tarquínios e, mais tarde, os conflitos entre a plebe e o patriciado pontuam a narrativa da vida republicana. Mas o que é peculiar às análises de Salústio é o reconhecimento (mesmo que seja ambivalente, como veremos) do caráter positivo do conflito e a convicção de que a tensão no interior da cidade resulta em benefício para a liberdade, o que fica bastante claro quando temos em mente que, algumas linhas antes da passagem citada, Memmius lembrava à plebe que seus antepassados haviam reagido à violência da nobreza se retirando, por duas vezes, da cidade em direção ao monte Aventino (SALÚSTIO, 2012a, p. 58). Essa forma de resistência possibilitou a criação do tribunato da plebe e a derrubada dos decênviros. No primeiro caso, a reação da plebe conduz à instituição de 
uma magistratura que contém os excessos dos patrícios em favor do bem coletivo e, no segundo caso, à dissolução de um regime despótico. É, portanto, a partir da resposta da plebe ao desejo de dominar (cura dominationis) que se cria e se conserva em Roma o espaço da liberdade.

Contudo (e aqui desponta a ambiguidade de Salústio com relação ao conflito), o antagonismo não parece, a seus olhos, constituir o modus vivendi político por excelência. O elogio da dissensão é circunstancial e ela jamais alcança o status de um operador político universal. Para dizer de outra forma, Salústio dá continuidade à tradição que fazia da concórdia e da paz os objetivos políticos mais elevados, assim como a condição para a vida política virtuosa. E é sob a condição de postular a superioridade do ideal da concórdia que Salústio pode fazer a história do nascimento dos conflitos em Roma. No capítulo XLI da Guerra de Jugurta, o historiador esboça a genealogia das lutas internas e da divisão da cidade em facções: "[...] antes da destruição de Cartago, o Senado e o povo romanos partilhavam o governo sem paixão e sem violência; nem a glória nem o poder acendiam a luta entre os cidadãos: o medo do inimigo mantinha a cidade no dever" (SALÚSTIO, 2012a, p. 76, tradução nossa, grifo nosso). A origem das facções remonta à supressão do medo frente ao inimigo externo. Desde que ele foi eliminado, "os males amigos da prosperidade, isto é, a licença e o orgulho, apareceram por sua vez" (SALÚSTIO, 2012a, p. 76, tradução nossa). Finda a guerra, a cidade encontrando o repouso, os romanos, que tanto desejavam a paz, se deparam com um mal ainda maior do que o conflito bélico:

A nobreza e o povo colocaram a serviço da paixão sua dignidade (a primeira) e sua liberdade (o segundo); cada um procura seu proveito pessoal, e começa 
a pilhar e a roubar. Tudo se transforma em objeto de disputa entre os dois partidos e a república, que até então se encontrava entre os dois, foi dilacerada (SALÚSTIO, 2012a, p. 76, tradução nossa).

Esta importante passagem nos coloca na pista que conduz ao coração da compreensão salustiana da história de Roma. De um lado, como já foi observado por muitos comentadores, o historiador faz o elogio do belicismo e do expansionismo romano, os quais teriam sido transmitidos aos humanistas do Renascimento, incluindo Maquiavel (SKINNER; VIROLI, 1990; HÖRNQVIST, 2004). Esta defesa do expansionismo apenas é compreendida à luz do reconhecimento do papel político do medo de um inimigo externo, sem o qual uma república se estagna e inicia seu processo de corrupção ${ }^{3}$. Antecipando um argumento que ecoará em Hobbes, para Salústio o medo produz a unidade interna e, consequentemente, a guerra adquire seu valor político somente se é travada contra o inimigo público (hostis). O conflito, portanto, desdobra sua verdadeira potência política quando coloca uma cidade contra outra (ou contra um outro). Mas, por outro lado, a divisão engendrada pela corrupção não encontra outra solução senão na resistência da plebe frente à insolência da nobreza. Salústio não esconde sua convicção de que a plebe, cuja paixão peculiar é a liberdade, é a única habilitada a frear os excessos do patriciado e o processo de degeneração que ameaça toda a república. Esta capacidade política da plebe é demonstrada pela história de Roma. A Guerra de Jugurta pode ser lida como a história da vitória da plebe sobre a nobreza: uma guerra que

\footnotetext{
3 Para uma apreciação do papel do medo no pensamento de Salústio, vale a pena consultar o livro de Daniel Kapust (2011), especialmente os capítulos 2 e 3.
} 
havia começado de maneira desastrosa pelo senado encontra um final honroso graças às decisões da plebe, dentre as quais a mais importante foi a nomeação de Mário como cônsul em 105 a. C., este homo novus (não pertencente a uma família nobre) que obterá a glória militar derrotando Jugurta e colocando a Numídia definitivamente sob o jugo de Roma.

Porém, a confiança de Salústio na plebe não é incondicional. Primeiramente, ela se justifica somente quando a nobreza esqueceu sua qualidade primeira, a dignitas, em favor dos interesses mais vulgares, da ambição e da cobiça. Em segundo lugar, Salústio não poupa a plebe, como vemos em sua versão da conjuração de Catilina, de críticas duras. Afinal de contas, ela apoiou, movida pelo "amor às mudanças", o projeto tirânico de Catilina (SALÚSTIO, 2012b, p. 64). A plebe, diz ainda Salústio, pode igualmente ser movida "pelo desejo de dominar (studio dominandi)" (SALÚSTIO, 2012b, p. 58, tradução nossa) e pegar em armas contra a nobreza. E, em terceiro lugar, vale observar que a narrativa da guerra de Jugurta assinala no horizonte da história de Roma o aparecimento dos protagonistas que conduzirão a cidade para sua mais sangrenta guerra civil, precisamente Mário e Silas. Salústio expõe sem ambiguidades o fascínio que eles puderam exercer (especialmente o primeiro) sobre a plebe e como ela pode alimentar a criatura que irá destruir de maneira irreversível sua liberdade.

\section{2. $\bigcirc$ Conflito e os Desejos: Maquiavel \\ 2.1 História e Conceito}

A referência a Salústio cumpre a função de identificar um possível antecedente terminológico para a célebre 
distinção desejo de dominar/desejo de não ser dominado. Cumpre igualmente a função de colocar no centro das análises políticas a figura do povo como o guardião da liberdade. Contudo, isso não é o bastante, acredito, para definir Salústio como um verdadeiro precursor de Maquiavel, e é justamente por isso que o cotejamento entre os dois autores ganha interesse. $\mathrm{O}$ tratamento dado por Salústio ao tema do conflito abre uma via para aceder ao núcleo da concepção maquiaveliana, mas isso somente é possível porque os autores estão distantes e próximos ao mesmo tempo, isto é, porque entre eles é legítimo identificar fortes afinidades (como fizeram SKINNER, 1990; FONTANA, 2003; KAPUST, 2007; 2011). Para demonstrar essa hipótese, retomarei a afirmação que fiz alguns parágrafos acima, a saber, a de que o conflito, em Salústio, não pode ser considerado um operador conceitual ou, ainda, a de que o conflito não constitui um princípio de sua compreensão da política ${ }^{4}$.

Se a ideia de concordia continua a organizar a reflexão política salustiana é porque o conflito não transcende a dimensão histórica, diferentemente do que vemos em Maquiavel. O conflito, para Salústio, está sempre circunscrito, determinado pelas condições de sua aparição. É verdade que Salústio entende sua presença como algo fundamental para a mobilização das forças políticas, porém o esperado é seu desaparecimento assim que cada uma das partes, nobres e plebe, empreender

\footnotetext{
${ }^{4}$ Estou inteiramente de acordo com a seguinte declaração de Fontana: "In effect, it seems that Machiavelli is taking Memmius' thematic idea - product, it should be noted, of the very dissension and factionalism that Memmius appears to lament, and which was originally intended by Sallust as a critical analysis of post-Marian Rome - and generalizes it into a conceptual and theoretical category of political discourse. In so doing, he presents a novel and revolutionary interpretation of Roman republican institutions which moves away from the traditional emphasis on unity, order, and the tranquillitas necessary for the public good" (FONTANA, 2003, p. 92, grifo meu).
} 
a atividade política que lhes é própria. Finalmente, o conflito se dissolve na retomada da "normalidade" da vida política. Ora, para Maquiavel é justamente o contrário. $\mathrm{O}$ conflito não desaparece quando as partes da cidade realizam aquilo que lhe é próprio, sendo finalmente seu resultado. Mas o ponto que deve ser destacado neste momento é o seguinte: ao referir o conflito às circunstâncias que o engendram, Salústio o determina historicamente de maneira a assegurar sua resolução no tempo, o que significa que o conflito é totalmente historicizado, inteiramente apreendido na história. Consequentemente, os atores políticos que nele estão envolvidos são eles mesmos reduzidos à dimensão histórica. Mas não apenas: eles aparecem como classes histórica e socialmente bem definidas. A nobreza de que fala Salústio é efetivamente o patriciado romano (ao qual se acrescenta os cavaleiros), assim como a plebe denota os demais cidadãos que se encontram em determinada posição social e cuja origem pode ser perfeitamente remontada no tempo. E se os personagens são dessa forma delimitados, os desejos que os animam são igualmente determinados.

Maquiavel entende o conflito, os desejos e os atores políticos de modo muito diferente. Em primeiro lugar, é preciso observar que o lugar que ele reserva ao conflito transcende a dimensão histórica, sendo legítimo distinguir uma dimensão propriamente conceitual e outra propriamente temporal. Para nos convencer disso basta lembrar que, no mais das vezes, o florentino estende universalmente o conflito que divide a cidade entre grandes e povo. Mas apenas pode fazê-lo sob a condição de estender igualmente os desejos dos grandes e do povo. A título de exemplo, no capítulo IX de O príncipe ele diz que "em toda cidade se encontram os diversos humores" (MAQUIAVEL, 2001, p. 100, tradução nossa) que levam ao 
conflito. Dupla extensão, portanto, o que implica afirmar duas generalizações que tornam impossível a restrição no espaço e no tempo, seja dos humores seja do conflito. Com essa extensão dos desejos e dos conflitos, Maquiavel cria operadores conceituais que o capacitam a compreender os acontecimentos políticos em sua particularidade e em sua generalidade, trabalhando em um duplo registro: o histórico e o conceitual ${ }^{5}$. No primeiro, ganha proeminência a especificidade da situação conflitiva em um determinado contexto político; no segundo, conflito e desejos são trabalhados como conceitos do pensamento político.

A partir do que foi avançado até agora, gostaria de observar dois pontos. O primeiro deles, que não vou desenvolver, diz respeito à relação entre os dois registros, isto é, o histórico e o conceitual. Eles são irredutíveis, porém não são independentes. O pensamento de Maquiavel jamais abandona a dimensão histórica, mesmo em seus momentos mais especulativos, e é justamente a conservação desse "lastro" que o impede de fazer um enquadramento da política com categorias que lhe são originalmente estranhas (ou, ainda, é essa "metodologia" que o permite compreender o sentido da política a partir de seu interior). O segundo ponto, que interessa analisar de

\footnotetext{
5 Vale notar que estou fazendo aqui um uso restrito do termo "história", reduzindo-o à narrativa dos acontecimentos. Em sua acepção ampliada, mais rica, a história é tanto o discurso que recolhe os eventos em sua particularidade quanto aquele em que eles ganham sua inteligibilidade a partir de princípios gerais. De acordo com essa última acepção, a história é o horizonte em que se insere a reflexão de Maquiavel, assim como a de Salústio (a respeito, ver ARANOVICH, 2007). E, ainda levando em conta essa acepção ampliada de história, é preciso fazer justiça a Salústio e reconhecer a natureza conceitual de seu trabalho de historiador. Os princípios gerais que lhe interessa formalizar são diferentes dos de Maquiavel, o que significa dizer que sua concepção da política é também diferente (Cf. KAPUST, 2011).
} 
modo pormenorizado, concerne à natureza do conflito e dos desejos quando não são mais compreendidos somente a partir da perspectiva histórica. Dizendo de outra forma: em que eles consistem quando os compreendemos como conceitos? A hipótese que gostaria de lançar, e que vai ocupar o resto deste texto, é a seguinte: o conflito e os desejos, uma vez "elevados" ao nível de conceitos, não comportam qualquer "substancialização", isto é, não podem ser explicados pela referência a qualquer elemento, salvo o elemento político. Isso significa que a psicologia e a antropologia (inegavelmente presentes em Maquiavel) devem ser remetidas seja à dimensão histórica (isto é, são evocadas para explicitar o quadro político específico em que os acontecimentos se desenrolam) seja à dimensão prática (são utilizadas para formular regras de prudência). Em um caso e em outro, jamais fundamentam o discurso maquiaveliano acerca do político (como bem demonstrou BIGNOTTO, 2008). Ora, na impossibilidade de sua "substancialização" torna-se imprescindível recorrer a uma interpretação de Maquiavel que enfatize o caráter negativo do desejo do povo, pois ela nos dá a chave para compreender a conceitualização operada pelo florentino.

\subsection{O Desejo do Povo}

Claude Lefort foi, certamente, o comentador que mais insistiu sobre o caráter "negativo" do desejo do povo (LEFORT, 1972, 1978, 1992), colocando em questão toda tentativa de identificação dos desejos políticos com o interesse de classe ou com uma inclinação antropológica. O que está em jogo é a "oposição constitutiva do político" e, por isso, a distinção entre grandes e povo não deve ser tomada como "uma distinção de 
fato, pois o que faz com que os Grandes sejam Grandes e que o povo seja o povo não é que eles tenham, por sua fortuna, por seus costumes, por suas funções um estatuto distinto associado a interesses específicos e divergentes". Antes, e Maquiavel o diz sem meias palavras, o que marca a posição específica de cada classe é que "uns desejam comandar e oprimir e os outros não sê-lo [...] uma classe não existe senão pela falta que a constitui em face da outra" (LEFORT, 1972, p. 382, tradução nossa). Dizendo de outra maneira, na perspectiva de Lefort as classes sociais não existem senão por seu enfrentamento (LEFORT, 1972, p. 385) e, por conseguinte, também os desejos políticos. Diante do desejo de dominar se erige o desejo de não ser dominado, sem que este pudesse adquirir qualquer concretude antes desse encontro. Nunca é demais repetir: Maquiavel define este desejo de forma negativa (não ser oprimido, não ser dominado), o que significa que seu conteúdo lhe é dado a partir de um elemento totalmente exterior ao agente (vale ainda lembrar que em certas passagens Maquiavel define esse "apetite" como o de não ser dominado "pelos Grandes". MAQUIAVEL, 2001, p. 100). Entretanto, é imprescindível ressaltar que o próprio agente é definido a partir do ato de desejar, em decorrência de sua natureza reativa. O ponto culminante da conceitualização maquiaveliana é atingido com o esvaziamento de todo conteúdo empírico, determinado, da classe que suporta esse desejo. Dizendo de outra maneira, o povo não é redutível a uma classe social ou econômica; antes, ele é o nome que adquire a classe política que opõe resistência ao desejo de dominação. Quanto aos grandes, o mesmo raciocínio deve valer, embora de forma mais nuançada porque seu desejo, como já observara Lefort (1972 e 1978), tem sua origem no desejo econômico de assegurar e ampliar seus bens. Mas apesar de fortemente associado ao interesse da classe 
abastada, o que define esse agente como agente político é o desejo de impor a dominação, o qual, transcendendo a esfera econômica, apenas pode ser adequadamente cifrado na linguagem política ${ }^{6}$.

A interpretação de Lefort me interessa por uma série de razões. Em primeiro lugar, ela acentua a natureza insuperável do conflito político, recusando-se a compreendê-lo como o inevitável derivado da divergência entre interesses ou como o resultado da diferença entre desejos que tendem a se afirmar. Este último será o modelo hobbesiano de conflito, o qual, finalmente, terminará por orientar boa parte das teorias contratualistas. Em contrapartida, a ideia de contrato não faz sentido em Maquiavel porque o conflito político é irresolúvel (LEFORT, 1972, p. 384-5). Em segundo lugar, enfatizando a natureza essencialmente política do confronto - sua irredutibilidade aos registros antropológico e econômico (LEFORT, 1978 e 1992) -, Lefort salienta o caráter negativo do desejo do povo, qualificando, por esse motivo, como o desejo de liberdade (LEFORT, 1972, p. 521-2) e o que habilita este desejo a cumprir esta função não é um dado natural à classe social que o sustenta, mas o fato de constituir uma resposta ao desejo de dominação. Ora, precisamente por isso o desejo do povo é, por excelência, o desejo político, comportando, no gesto de recusa à opressão, a única universalidade possível na vida política, vale dizer, aquela da negação e da indeterminação ${ }^{7}$.

\footnotetext{
${ }^{6}$ Como afirma S. Cardoso (2015, p. 243-4), "os grandes, movidos pela ambição de bens e de mando, por interesses particulares ou facciosos (de 'alguns'), definem-se como classe política somente por sua aversão - e seu ódio - ao povo e à repressão das leis. Só a oposição popular, portanto, faz deles classe e, assim, atores propriamente políticos".

7 Não querer ser dominado implica a extensão universal do desejo porque é recusa da particularidade da dominação, assim como de seu caráter determinado (LEFORT, 1978).
} 
E que este desejo do povo, desejo de liberdade, possa colocar a nu a questão do "ser da Cidade" (LEFORT, 1972, p. 523), questão recoberta pela ideologia, não é o menor de seus benefícios.

$\mathrm{O}$ ponto que gostaria de reter das análises de Lefort concerne, então, ao caráter negativo do desejo do povo. Vou deixar de lado as importantes consequências teóricas que dele deriva - especialmente no que concerne à sua relação com a lei ${ }^{8}$ - para sublinhar o caráter relativo (ou relacional) desse desejo. Acredito que valha a pena insistir sobre esse traço peculiar pois ele é, com frequência, esquecido pelos comentadores de Maquiavel. E não sem razão. Afinal de contas, Maquiavel utiliza um vocabulário que conduz facilmente o intérprete a tomar os desejos políticos em uma chave positiva. O termo "humores" (umori) remonta, como já foi exaustivamente observado, à tradição hipocrático-galênica (GAILLE-NIKODIMOV, 2004), o que torna natural sua identificação com princípios (substâncias) que animariam o corpo político à semelhança do que ocorre no corpo individual. Mas essa identificação, de meu ponto de vista, conduz a uma distorção na leitura do texto de Maquiavel que cabe corrigir de duas formas: insistindo sobre o caráter metafórico, quase alegórico da imagem dos humores e, em segundo lugar e, de maneira mais efetiva, enfatizando as passagens onde o desejo do povo é apresentado de modo claramente negativo.

Como de hábito, o quarto capítulo do livro I dos Discorsi sopra la prima Deca di Tito Livio servirá de referência principal. Em uma passagem central na argumentação em defesa do valor político dos "tumultos" em Roma, Maquiavel afirma o seguinte: "Os desejos dos povos livres raramente são

${ }^{8}$ A respeito ver o artigo de Sérgio Cardoso (2015). 
perniciosos à liberdade, porque nascem ou do fato de serem oprimidos ou da suspeita de que o serão" (MAQUIAVEL, 2000 , p. 72, tradução nossa, grifo nosso). O texto não poderia ser mais claro: o que desperta o desejo de liberdade é a realidade da opressão, ou o sentimento de que ela poderá se estabelecer. Sendo assim, este desejo nada tem de um elemento anterior à experiência política que pudesse comandá-la ou fundá-la à maneira de um princípio de ação. O desejo de liberdade é a reação do povo frente à ameaça da dominação. E é precisamente como enfrentamento a ela que se instaura o conflito no interior da cidade. Não deve causar surpresa o fato de sua manifestação ser originalmente, na história de Roma, também negativa (como vemos no capítulo 3 do mesmo livro dos Discorsi): a plebe recusa o serviço militar e se retira da cidade, tomando o monte Aventino. Não seria excessivo insistir sobre a natureza simbólica dessa retirada, para além de seu evidente resultado prático (a instituição dos tribunos da plebe $)^{9}$. Ao sair de Roma a plebe deixa um vazio na cidade, delimitando, de modo negativo, o lugar que ocupa. Com o mesmo gesto, assinala a especificidade de sua participação no poder: não se trata de reivindicá-lo para si mesma, em detrimento do Senado, mas, por meio da recusa da dominação, impedir sua apropriação por quem quer que seja.

Se entendermos esse vazio como o lugar da não dominação (criado a partir da manifestação do desejo de não dominação), veremos que as formas de participação política da plebe, por meio de seus representantes (os tribunos), a ele se referem necessariamente. O instituto da acusação pública,

\footnotetext{
${ }^{9}$ E valeria ainda a pena recordar outra retirada da plebe em um momento crucial da história romana, aquele que corresponde à resistência à tirania dos decênviros, comentado por Maquiavel em Discorsi, I, 40.
} 
que Maquiavel elogia no capítulo sete do primeiro livro dos Discorsi, não tem outra função a não ser preservar a liberdade quando ela ameaça ser ocupada ${ }^{10}$ por um cidadão ambicioso (MAQUIAVEL, 2000, p. 79-82). Mais ainda, as próprias leis não podem ser compreendidas sem esse "trabalho do negativo" operado pelo desejo de não ser oprimido (Cf. LEFORT, 1972, p. 477) porque elas mesmas são, essencialmente, a recusa da dominação sob forma institucionalizada.

$\mathrm{O}$ que me parece crucial, contudo, é que nessa presença "negativa" se assinala o fato político fundamental: a plebe e, por extensão, o povo, não pode ser reduzida a nenhuma de suas figurações históricas. É verdade que, em Maquiavel, o registro histórico não é simplesmente aquele em que os desejos dos Grandes e do povo ganham "efetividade". Ele é igualmente o domínio em que os "diversos apetites" entram em cena e turvam a imagem diáfana produzida pela distinção conceitual. Assim, Maquiavel vai nos mostrar que o desejo de não ser oprimido convive com outras espécies de apetite. Por exemplo, a resistência à dominação geralmente está associada ao desejo de segurança e de conservação da propriedade ${ }^{11}$. Vale ainda lembrar as várias passagens em que Maquiavel se refere ao desejo de vingança do povo ${ }^{12}$. Os Grandes, por sua vez, são comumente afetados pela cobiça (como, aliás, já denunciava Salústio), pela ambição ou pelo desejo de glória. Todos esses desejos têm um conteúdo mais ou menos determinado e, como tais, são dedutíveis da natureza da alma

\footnotetext{
${ }^{10}$ É importante, aliás, ressaltar a constante presença dessa expressão em Maquiavel, herança dos escritores latinos, como o próprio Salústio.

${ }^{11}$ Como vemos em Discorsi, II, 2.

${ }^{12}$ Cf. O principe, VII; Discorsi, I, 7 e 8; História de Florença, livro II.
} 
humana. Contudo, é preciso evitar a armadilha de tomar esses desejos "empíricos" como a chave de compreensão dos desejos que estruturam a oposição fundamental dominar/não ser dominado. Certamente, eles cumprem uma função explicativa, sendo, em muitos casos, identificados como a causa imediata de determinados acontecimentos. Porém, Maquiavel jamais se apoia sobre eles para construir sua teoria do conflito. Se o capítulo 4 do primeiro livro dos Discorsi não é suficiente para convencer da plausibilidade dessa proposição, gostaria de me servir do capítulo 37, também do livro I dos Discorsi, em especial por causa do protagonismo que aí desempenha a noção de necessidade.

\subsection{Necessidade e Desejo}

A propósito do tema da necessidade Maquiavel, sobretudo no primeiro livro dos Discorsi, faz algumas observações que são importantes destacar. O tema aparece logo nos capítulos iniciais, onde estão em discussão as diversas possibilidades de fundação da cidade e como esta determina seu destino político. Toda a ênfase é colocada sobre a virtù, seja aquela do fundador, imprescindível para o "bom começo", seja a do povo, requerida para a conservação da comunidade política. Ora, Maquiavel não deixa dúvidas de que a virtù não pode ser identificada com uma qualidade natural de um certo povo. Antes, ela resulta do artifício, como resultado da ação do fundador, ou da própria natureza, isto é, as circunstâncias que determinam as condições da fundação. Como quer que seja, a virtù não nasce espontaneamente, mas é forjada pela dureza das condições ou pelas leis introduzidas pelo fundador. 
Em um e outro caso, ela resulta da necessidade (MAQUIAVEL, 2000, p. 62-63) $)^{13}$.

Mas é no capítulo 37, ao examinar o problema da corrupção da república romana, que Maquiavel faz uma notável formulação a respeito da necessidade. Apesar de um pouco longa, é imprescindível citar a passagem na íntegra:

Os escritores antigos diziam que os homens costumam afligir-se no mal e aborrecer-se no bem; e que de uma ou outra dessas paixões costumam nascer os mesmos efeitos porque toda vez que os homens não combatem por necessidade, combatem por ambição, a qual é tão poderosa no espírito do homem que jamais, em qualquer grau que seja, o abandona. A razão é que a natureza criou os homens de modo que podem desejar todas as coisas e não podem conseguir todas as coisas, de modo que, sendo o desejo sempre maior do que a potência de conquistar, resulta o descontentamento com aquilo que se possui, e a pouca satisfação. Dai se origina a variação de sua fortuna: os homens, desejando em parte adquirir mais e em parte não perder o que conquistaram, conhecem a inimizade e a guerra, das quais nascem a ruína de um país e a prosperidade de um outro (MAQUIAVEL, 2000, p. 139-140, tradução nossa, grifo nosso).

Maquiavel desenha aqui o quadro interpretativo que lhe permite explicar não somente a perda da liberdade romana, em particular, mas o mecanismo da corrupção, em geral. As origens da tirania em Roma e, por extensão, as causas da ruína de todas as repúblicas se encontram na substituição da necessidade pela ambição. Uma e outra configuram dois

${ }^{13}$ A mesma proposição é novamente formulada no capítulo 3, quando Maquiavel afirma que os homens apenas fazem o bem "onde há necessidade" (MAQUIAVEL, 2000, p. 70). 
modos de combater na cidade, ou seja, são dois princípios de ação. A ambição funda suas raízes na natureza humana e, nesse sentido, encerra o campo da ação política dentro de limites estreitos, desenhados pela psicologia das paixões (tão bem descrita por Hobbes no século seguinte ao de Maquiavel). A necessidade, por sua vez, desarticula a lógica das paixões, introduzindo um elemento da realidade, um dado externo ao espírito do homem e ao círculo de seus apetites: a violência da dominação ${ }^{14}$. A lógica da necessidade é caracterizada pela imperatividade. Ela é o aguilhão que obriga os homens a agirem, em detrimento (o que não significa sempre contrariamente) do que possam desejar. Seu efeito no campo político é notável: ela conduz os homens a agirem de maneira distinta daquela que sua suposta natureza determina. E o que determina a natureza para o homem? Desejar adquirir, conquistar e preservar o que foi conquistado. Ora, desses apetites naturais não é possível deduzir a política nem estabelecer a liberdade, uma vez que o que engendra a vida cívica não são esses desejos e sim a recusa a submeter-se à sua lógica imperativa. Este argumento é o cerne do capítulo 37.

A conquista da liberdade ${ }^{15}$ romana e também sua perda são compreendidas a partir desse esquema apresentado nas linhas iniciais. O que determinou a decadência da república foi precisamente a substituição do combater pela necessidade pelo combater pela ambição. Mas onde se detecta essa substituição? Na plebe, isto é, no agente político que deve suportar o desejo de não ser oprimido. Após a reintrodução das leis agrárias pelo Gracos, diz Maquiavel, a plebe começa a desejar como os

\footnotetext{
${ }^{14}$ Se voltarmos ao capítulo 3, esta violência é descrita como as insuportáveis e constantes "ofensas" da nobreza, que levaram a plebe a se rebelar.

15 Como vemos no capítulo 3 do livro I.
} 
nobres, pleiteando honrarias e riquezas: não era mais suficiente para ela, escreve Maquiavel, "assegurar-se dos nobres pela criação dos Tribunos, ao qual desejo foi conduzida por necessidade. Obtido isto, ela começou a combater por ambição e a querer com a nobreza dividir as honras e os bens (substanze), como as coisas mais estimadas pelos homens" (MAQUIAVEL, 2000, p. 140, tradução nossa).

Chegamos então ao ponto que queríamos: a genealogia do desejo de não ser dominado explicita seu caráter não natural, ou mesmo "artificial" ou "tardio". Ele surge em decorrência da dominação, como a resposta que o povo romano deu aos patrícios após a expulsão dos Tarquínios, como descrito em Discorsi, I, 3. O aguilhão da necessidade desaparecendo, os homens se fecham em sua particularidade, mesmo que seja a particularidade de uma classe, imperando a lógica dos apetites "naturais" dos homens. Vale lembrar que a ruína romana decorreu das tentativas de implementação da lei agrária pelos Gracos. Apesar do espírito público que a motivava, apesar do espírito cívico dos tribunos, sua retomada resultou catastrófica porque dava azo para que a plebe satisfizesse sua ambição natural (ela desejava como os Grandes), o que não poderia deixar de suscitar a reação violenta da parte dos nobres. Por conseguinte, Roma estava entregue à luta de facções e o conflito que então surgia adquiria uma forma diferente do conflito anterior porque não se tratava mais do antagonismo entre dois desejos essencialmente opostos, e sim do embate entre dois desejos que queriam a mesma coisa, a saber, as riquezas. Nessa deposição do espírito público, que coincide com o próprio desaparecimento da política, ou sua redução a mero jogo de interesses, a liberdade está prestes a se extinguir, juntamente com os meios institucionais para a resolução do conflito: as 
vias de ação em tais circunstâncias são aquelas que Maquiavel denomina de "extraordinárias".

A destruição da liberdade, que define a corrupção da república, não é outra coisa além da substituição do desejo de não ser dominado pela dinâmica dos apetites. Esta dinâmica, por corresponder à condição humana em geral, torna homogêneas as classes políticas, terminando por eclipsar o espaço público em proveito de sua privatização, quer dizer, sua ocupação por facções. A lição que Maquiavel extrai do episódio dos Gracos é a de que a vida cívica e a liberdade apenas existem onde é conservada a oposição fundamental, o que não se consegue sem a constante remissão ao momento originário do político, o conflito no qual uma parte da cidade vem dizer não àqueles que desejam dominar. Este momento de instituição do político e os desejos que aí atuam são, primeiramente, figuras conceituais e não históricas. Mas isso não significa que não possam configurar-se na história e comandar a prática política que visa à liberdade.

\section{Conclusão}

A principal hipótese que tentei examinar neste trabalho pode ser formulada nos seguintes termos: a teoria maquiaveliana dos humores não pode ser deduzida de uma determinada concepção da natureza humana, apesar das inúmeras considerações antropológicas e psicológicas presentes em sua obra. Isso significa aceitar a proposta, avançada por Claude Lefort, de tomar Maquiavel como um pensador que se interessa primordialmente pela "natureza da cidade" (LEFORT, 1992, p. 171). Mas significa igualmente assumir que os 
desejos políticos - dominar e não ser dominado - não encontram seu fundamento na natureza humana e, por isso, não podem ser tomados como elementos que antecedem e informam a vida política a partir de uma esfera extra-política. Contudo, o conflito não oferece por si só as condições de inteligibilidade da divisão política, o que significa que a oposição dominar/ não querer ser dominado tem de ser referida a um dado das relações sociais, qual seja, a violência da dominação. A necessidade, que está na origem da resistência à dominação, opera como a força instigadora que induz os seres humanos a modificar sua condição de dominados. O que vai definir o desejo político do povo é exatamente o impulso para por fim à dominação dos grandes, como, aliás, Salústio havia identificado na história romana.

É inútil, portanto, buscar o lastro do desejo de não ser dominado em algum elemento da natureza humana ou da psicologia das paixões. Como resposta à dominação violenta, não se pode compreender esse desejo fora do âmbito das relações de poder (o mesmo se aplicando para o desejo de dominar). E vale notar que ele é imprescindível para a criação do espaço político, sendo a condição sem a qual não é possível a liberdade. Pelo mesmo motivo, esse desejo é facilmente conjugado com o desejo de viver sob as leis (embora não lhe seja idêntico $)^{16}$, uma vez que sua operação primeira é barrar a supremacia de um grupo (ou de um indivíduo) sobre outro. Nascido sob a égide da necessidade, seu aparecimento coincide com a criação da coisa pública e, por isso, é perfeitamente compreensível que seu "titular" seja o mais habilitado a con-

\footnotetext{
${ }^{16}$ Não sendo possível desenvolver este tema aqui, apenas indico uma passagem crucial do segundo livro da História de Florença em que Maquiavel entende o desejo do povo como o de "vivere secondo le leggi".
} 
servá-la. Em contrapartida, seu desaparecimento é a própria definição da corrupção.

Que esses desejos mantenham relação com os diversos apetites humanos aos quais Maquiavel reserva um papel não negligenciável na vida política (como motivos da ação individual) não deve nos levar a confundir os registros de sua análise. A mesma precaução metodológica vale no que diz respeito à atribuição dos desejos às classes sociais: "povo" e "grandes" se definem, em última instância, por seu posicionamento no conflito que institui o campo do político. Certamente, Maquiavel demonstra ter aprendido a lição de Salústio ao localizar no centro da vida política romana (e, por extensão, no centro de todas as cidades) a tensão que divide as classes sociais. Mas se afasta definitivamente do historiador romano ao identificar no conflito o sinal mais evidente da irredutibilidade do político, isto é, sua afirmação como um dos âmbitos da existência humana que não pode ser simplesmente derivado dos demais, o que não pode ser devidamente compreendido se desconsiderarmos o caráter radicalmente negativo do desejo do povo.

\section{Referências}

AMES, José Luiz. "Liberdade e Conflito. O Confronto dos Desejos como Fundamento da Ideia de Liberdade em Maquiavel”. Kriterion, Belo Horizonte, n. 119, p. 179-196, 2009.

ARANOVICH, P. História e política em Maquiavel. São Paulo: Discurso, 2007.

BIGNOTTO, Newton. Maquiavel republicano. São Paulo: Loyola, 1991. 
"A Antropologia Negativa de Maquiavel". In: Analytica, Vol. 12, n. 2, p. 77-100, 2008.

. "Lefort and Machiavelli". In: Martin Plot (Org). Claude Lefort. Thinker of the Political. Nova York: Palgrave and Macmillan, 2013. p. 34-50.

CARDOSO, Sérgio. "Em Direção ao Núcleo da 'Obra Maquiavel': sobre a Divisão Civil e suas Interpretações”. In: Discurso, $\mathrm{n}^{\mathrm{o}} 45 / 2$, p. 207-248, 2015.

CONNOLY, Joy. The state of speech. Rhetoric and Political Thought in Ancient Rome. Princeton: Princeton University Press, 2007.

FLYNN, Bernard. The philosophy of Claude Lefort. Interpreting the political. Evanston: Northwestern University Press, 2005.

FONTANA, Benedetto. "Sallust and the Politics of Machiavelli". In: History of Political Thought, Vol. 4, n. 1, p. 86-108, primavera de 2007.

GAILLE-NIKODIMOV, Marie. Conflit civil et liberté. Paris: Honoré Champion, 2004.

HÖRNQVIST, Mikael. Machiavelli and empire. Cambridge: Cambridge University Press, 2004.

KAPUST, Daniel. "Cato's Virtues and The Prince: Reading Sallust's War with Catiline with Machiavelli's The Prince. In: History of Political Thought, Vol. 28, n. 3, p. 433-448, outono de 2007. 
. Republicanism, Rhetoric, and Roman Political Thought. Sallust, Livy, and Tacitus. Cambridge: Cambridge University Press, 2011.

LEFORT, Claude. Le travail d'œuvre. Machiavel. Paris: Gallimard, 1972.

. Les formes de l'Histoire. Paris: Gallimard, 1978.

. "Machiavel et la Verità Effettuale. In: Écrire. A lépreuve du politique. Paris: Calman-Lévy, 1992. p. 141-179.

MAQUIAVEL, Nicolau. Le prince - Il principe. Ed. bilíngue. Trad. de J. L. Fournel e C. Zancarini. Paris: PUF, 2001.

. Discorsi sopra la prima deca di Tito Livio. Milão: Rizzoli, 2000.

SALÚSTIO. La guerre de Jugurtha. Ed. bilíngue. Trad. de A. Ernout. Paris: Belles Lettres, 2012a.

. La conjuration de Catilina. Ed. bilíngue. Trad. de A. Ernout. Paris: Belles Lettres, 2012b.

SKINNER, Quentin. "Machiavelli's Discorsi and the PreHumanist Origins of Republican Ideas". In: BOCK, Gisella; SKINNER, Quentin; VIROLI, Maurizio. Machiavelli and Republicanism. Cambridge: Cambridge University Press, 1990. p. 121-142.

VIROLI, Maurizio. "Machiavelli and the Republican Idea of Politics". In: BOCK, Gisella; SKINNER, Quentin; VIROLI, Maurizio. Machiavelli and Republicanism. Cambridge: Cambridge University Press, 1990. p. 143-172. 